\title{
Quasi-UD glass fibre NCF composites for wind energy applications: a review of requirements and existing fatigue data for blade materials
}

\author{
Katleen Vallons ${ }^{1, a}$, Georg Adolphs ${ }^{2}$, Paul Lucas $^{3}$, Stepan V. Lomov $^{1}$ \\ AND IGNAAS VERPOEST ${ }^{1}$ \\ 1 Department of Materials Engineering, Katholieke Universiteit Leuven, Belgium \\ 2 Owens Corning, Composites Solutions Business, Sant Vicenç de Castellet, Spain \\ 3 Owens Corning, Composites Solutions Business, Science \& Technology Center, Chambéry, France
}

Received 3 April 2012, Accepted 16 January 2013

\begin{abstract}
Quasi-unidirectional glass fibre non crimp fabric composites are routinely used in wind energy applications. An important factor to consider in this type of application is the fatigue behaviour of the materials. The present paper gives an overview of the current approach to material fatigue testing and design in the wind energy industry, as well as a review of available material data for the fatigue of unidirectional glass fibre composites. Both "pure" unidirectional and quasi-unidirectional (NCF-based) materials are considered.
\end{abstract}

Key words: Fabrics / textiles / fatigue / stitching

\section{Introduction}

Under the impulse of renewable and sustainable energy considerations, the global wind energy industry has seen a remarkable expansion over the past few decades. Since most wind turbines are constructed at least partially from composites, the wind industry has become an important composite material end user market.

Two of the most important concerns for wind turbine manufacturers are the durability and the cost of their products. These are interrelated, because repairs on prematurely failing turbine parts can bring about significant extra costs. Durability means that the turbine and all of its components do not fail until they have reached their design lifetime. This implies the use of materials with well-known characteristics, especially in the field of strength and fatigue behaviour, and also the application of "fail-proof" design techniques, usually involving relatively high safety factors. From the cost perspective, however, it is beneficial to limit the amount of material used and to reduce the weight of the component. This means reducing the amount of "over-design" and thus reducing the applied safety factors. This can only be done if the properties of the applied materials are reliably known,

\footnotetext{
a Corresponding author:

Katleen.vallons@mtm.kuleuven.be
}

as well as the precise load conditions for the final components. The present approach to material evaluation in wind turbine design, however, is not oriented towards reducing the variability in the material properties, or investigating reasons for material failure.

Since an important requirement for wind turbines is durability, they are usually produced from strong and fatigue-resistant materials. For the turbine blades, this is most often a type of composite. Because of the complex shape of the blades and the flexibility of the production process, nowadays, nearly all manufacturers use textile reinforcements for the composites. Non crimp fabrics (NCF) are the most used textile type. In general, these consist of unidirectional (UD) fibre layers that are stitched together with a thin yarn (see Figs. 1a and b). Because of this process, these fabrics exhibit very limited amounts of crimp, causing the properties of the final composites to be very close to those of prepreg-based counterparts. However, the stitching process also introduces artefacts that can influence the final properties of the material. These artefacts are dependent on the textile production parameters and as such, the latter may indirectly influence the behaviour of the produced composites.

This paper is intended as a review, giving an overview of general design requirements for wind turbine blades, as well as the current approach to material fatigue testing in the wind energy industry. Apart from that, a review 

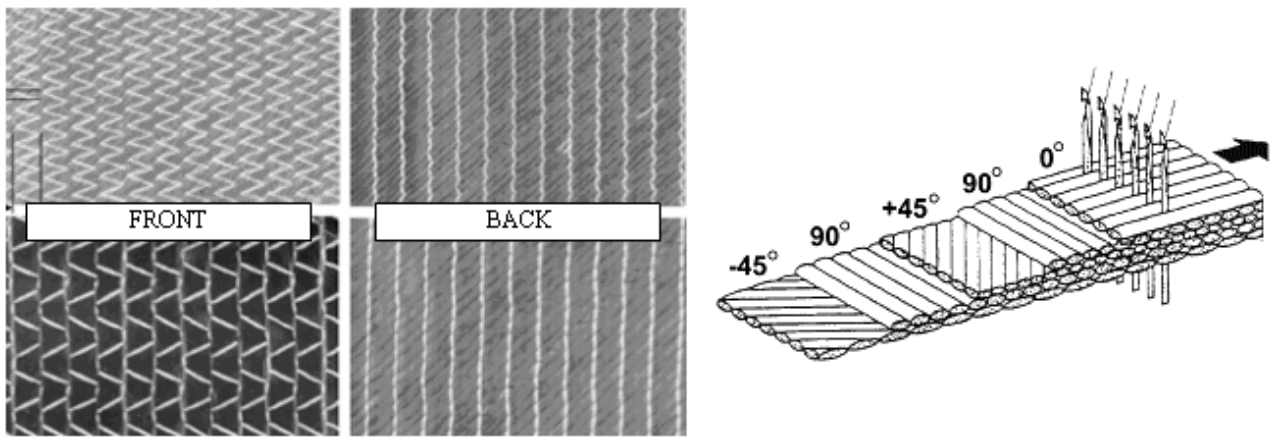

(a)

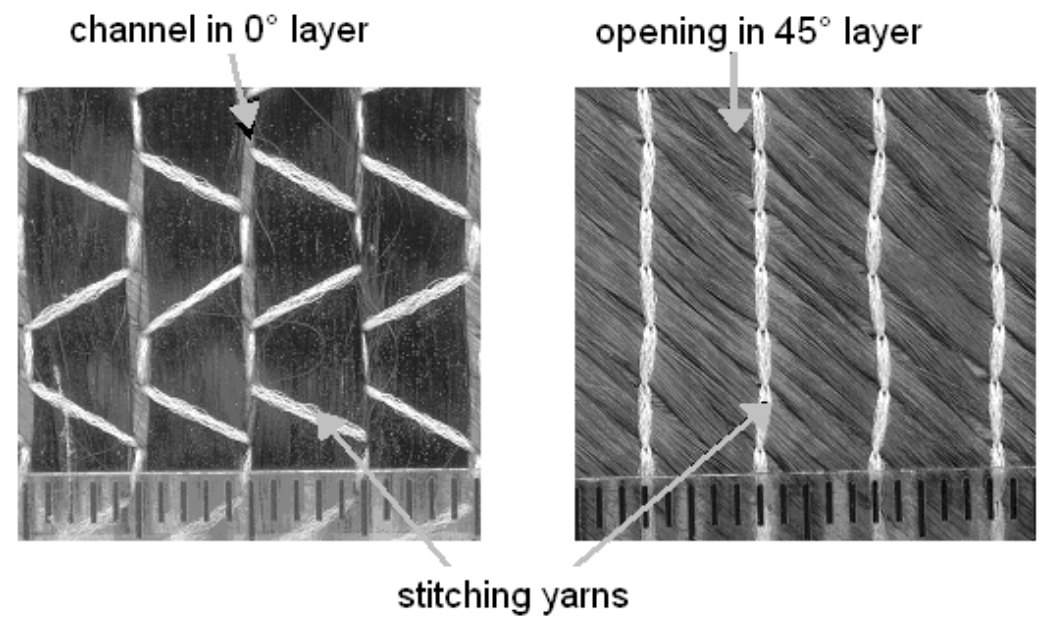

(b)

Fig. 1. (a) Picture of two carbon fibre non crimp fabrics, and schematic illustration of the production of non crimp fabrics (www.liba.de), and (b) illustration of the channels and openings created by the stitching process in a $0^{\circ}$ oriented fibre layer (left) and a $45^{\circ}$ oriented fibre layer (right) in a multiaxial NCF.

of existing relevant fatigue data for unidirectional glass fibre composites, including NCF based composites, is also provided.

\section{General design and material requirements for wind turbine blades}

Wind turbines blades are complex structures. Figure 2a shows a schematic representation of a typical wind turbine blade. As illustrated in the figure, the local shape of the cross-section varies along the blade axis. Two often used types of blade design are shown in Figure 2b. The most common design consists of one or more shear webs with spar caps, carrying about $90 \%$ of the load, and an outer shell, which main function it is to provide the aerodynamic shape. The shell also plays a role in the resistance of the blade to torsion. Other designs are also used, e.g. with a central spar box instead of shear webs (see Fig. 2b) [1].

Environmental conditions in the neighbourhood of wind turbines can vary greatly, and as such, the blades experience a multitude of different load cases during their lifespan. These all need to be taken into account in the design of the components. This section introduces the important properties and requirements for wind turbine blade materials and the types of materials that are currently used for these applications.

\subsection{Design aspects}

The design of wind turbines, and wind turbine blades in specific, takes into account numerous loading cases, as defined in relevant standards e.g. [2,3]. Important are survival loads, extreme operational loads, and long term durability. Survival loads, also called extreme loads, are the maximum loads the construction is expected to withstand, e.g. a hurricane or an earthquake. Extreme operational loads are the highest loads that will be experienced during normal operation of the turbine. Durability implies the fail-free functioning of the construction under normal circumstances for the designed service life, which is typically 20-25 years. 


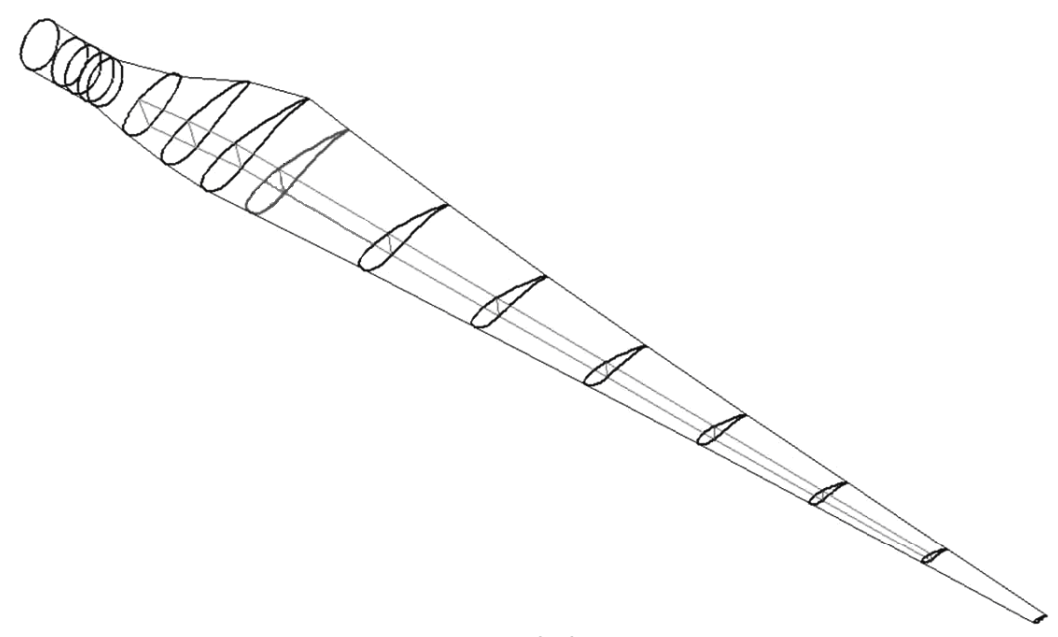

(a)

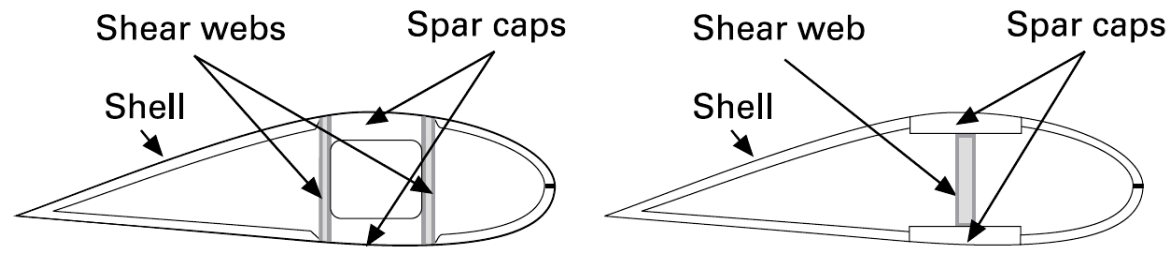

(b)

Fig. 2. Schematic illustration of a wind turbine blade, (a) indicating the varying cross-section along the blade axis [79], and (b) two possible designs for the cross-section of a wind turbine blade. Left: structural spar box concept and right: structural shell/shear web concept. Adapted from [80].

The different minimum design requirements, relevant load cases and wind conditions for wind turbines are described in standards such as IEC 61400 part 1 [2]. The standard requires the use of a structural dynamics model to predict the design loads for the wind turbine from data on the external conditions. Such a model should be used to determine the loads for different design situations, wind speeds and turbulence conditions, which are also defined in the standard.

Based on the prevalent wind conditions (average wind speed and turbulence characteristics), the wind turbine is assigned to a certain wind turbine class (ranging from $I_{\mathrm{A}}$ to $\left.I I I_{\mathrm{C}}\right)$. The turbine will then be designed to safely withstand the wind conditions defined by the appropriate wind turbine class [2].

The external conditions for wind turbines can be subdivided into normal and extreme categories. The normal external conditions generally concern recurrent structural loading conditions, which will occur frequently during normal operation, while the extreme external conditions represent design conditions that have for example a 1-year or a 50-year recurrence period. The design load cases for the wind turbine consist of potentially critical combinations of these external conditions with wind turbine operational modes and other design situations.

Obviously, the primary external conditions affecting the structural integrity of wind turbines are the wind conditions, with for example hurricanes as extreme conditions. Figure 3 gives an overview of the external dynamic forces that work on a wind turbine. The various vibration and deflection modes of the turbine are also shown. The picture illustrates the complexity involved in the design of wind turbines. Other environmental conditions of importance for wind turbines are for example temperature, humidity, salinity, lightning and earthquakes [2]. Apart from that, also loads related to singular events as impact are important.

The repeated loads on the turbine that cause fatigue of the blades are all operational loads and/or caused by operational loads, such as vibration due to rotation or wind gusts. The full blade is subjected to axial tension and compression loads during turbine operation, as well as to flapwise and edgewise bending and torsion. The blades are designed in such a way that the spar caps are loaded axially in tension/compression, and the shear webs in shear.

Figure 4a shows a cross-section of a blade (with a single shear web design), illustrating the different loading types in the different areas of the blade. The spar caps are normally loaded in the axial direction, while the shear web(s) are mainly loaded in shear. The outer shell also experiences some shear forces, arising from torsion of the blade. Often, some reinforcements are also incorporated in the shell to prevent it from buckling under compressive loads. 

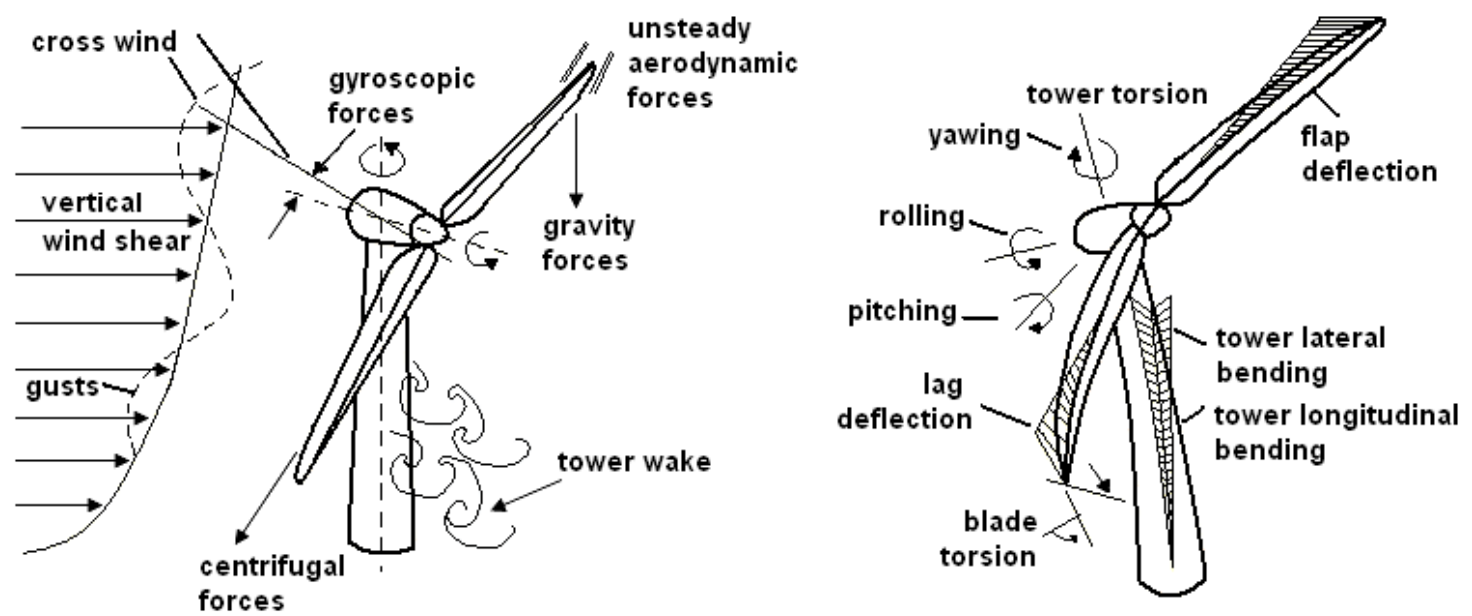

Fig. 3. Load conditions of a wind turbine: left: the external dynamic forces that work on a turbine. Right: the various vibration and deflection modes of a wind turbine. Adapted from [81].

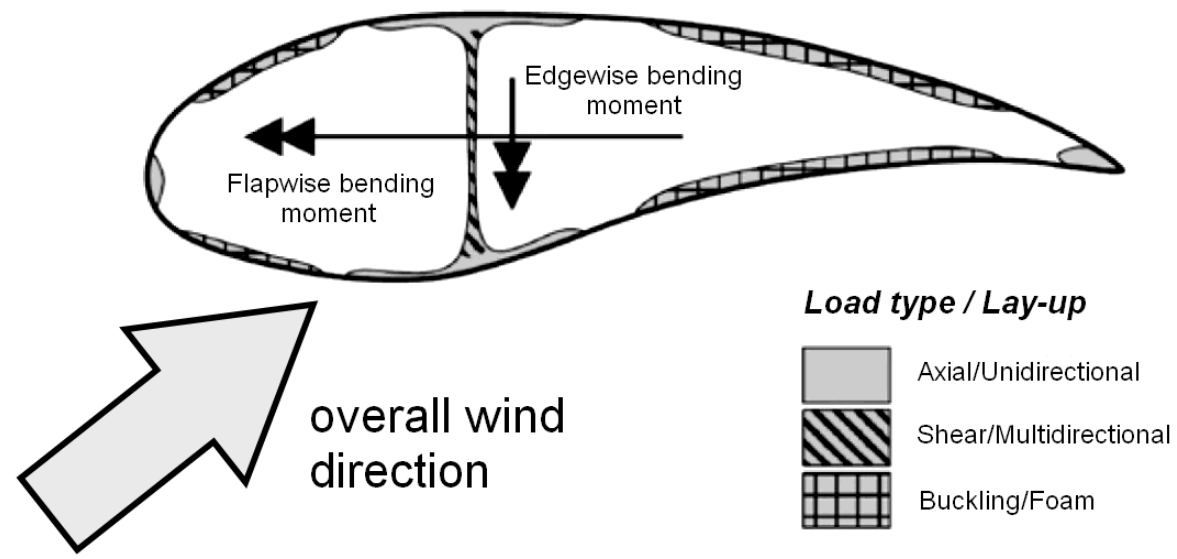

(a)

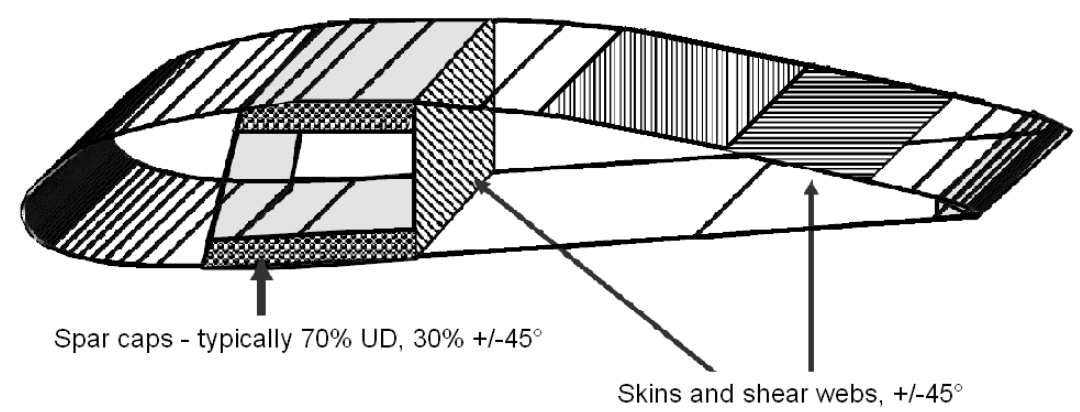

(b)

Fig. 4. (a) Illustration of the loading types and associated fibre lay-up in the different areas of a blade with single shear web design, and (b) typical fibre orientation in the different components of a turbine blade. Adapted from [82]. 
Table 1. Overview of materials commonly used for wind turbine blades.

Matrix material

Unsaturated polyester

Vinylester

Epoxy

Small-size turbines: polypropylene, polyamide

\section{Fibre material}

Glass fibre $\left(E\right.$-glass, Advantex $\left.{ }^{\circledR}, \ldots\right)$

Carbon fibre

Basalt fibre

Reinforcement architecture

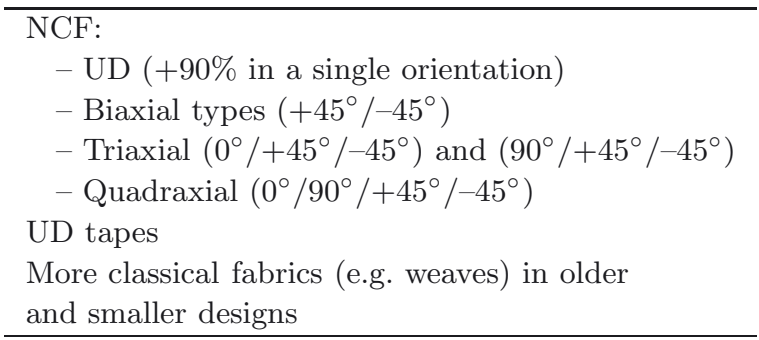

To account for the uncertainties and variability in loads and materials, the uncertainties in the analysis methods and the importance of structural components with respect to the consequences of failure, partial safety factors are used in the ultimate limit state analysis for the design of a wind turbine. Minimal values for these partial safety factors are also listed in the standards and guidelines, e.g. [2-4].

The design of wind turbine components is verified according to specific guidelines by technical surveillance organizations such as GL (Germanischer Lloyd), DNV (Det Norske Veritas) or TÜV (Technischer ÜberwachungsVerein) [3-10].

\subsection{Material aspects}

Wind turbine blades are large, quasi continuously moving structures, and are subject to highly variable loads. Consequently, materials are required that are light, strong and fatigue resistant. Ideally, they should also be unaffected by environmental conditions such as rain and salinity. Generally, the material of choice for the blades of wind turbines is a type of glass fibre composite. Although carbon fibre composites are lighter and stronger, they are only used for parts of the largest types of blades, mainly because of their much higher cost. Table 1 gives an overview of typical materials used for the production of composites for wind turbine blades.

Glass rovings of various glass qualities are used, like $E$-glass or more advanced, producer specific formulations as Advantex ${ }^{\circledR}$ glass reinforcement or High Performance Glass. Rovings with 300, 600, 1200, or 2400 Tex are frequently used.
In the beginning of the series production of rotor blades, the resin material for the glass fibre composites was usually an unsaturated polyester, because of its relatively low price. With the growth of the rotor blades, manufacturers have begun to show more interest in epoxy resins. This is mainly due to the lower percentage of shrinkage of the latter (about 2-5\%) compared to that of an unsaturated polyester (about 5-12\%), and to the slightly higher thermomechanical properties [11].

Figure $4 \mathrm{~b}$ illustrates the orientation of the fibres in the composite material in different areas of a typical blade (see also Fig. 4a). As the figure shows, for the spar caps, mainly unidirectional structures are used, built up either by prepregs or by vacuum infused quasi-UD NCF fabrics [12]. As mentioned in the introduction, NCFs, or Non Crimp Fabrics, are dry textile reinforcements that consist of unidirectional fibre layers that are stitched together with a thin yarn. Since the fibres in the different layers remain virtually straight, this type of textile has a very limited crimp, an important advantage compared to other textiles like woven fabrics, as the low crimp results in a better mechanical performance. Quasi-UD NCFs in practice usually consist of one unidirectional $\left(0^{\circ}\right)$ layer, stabilised by adding a limited amount of $90^{\circ}$ oriented fibre bundles.

Figure $4 \mathrm{~b}$ also shows that for the shear webs and the skins, $+45^{\circ} /-45^{\circ}$ fibre orientations are applied, to reduce twist of the blades and to resist shear forces. Mostly, biaxial NCFs with fibre orientations $\pm 45^{\circ}$ are used. Triaxial NCFs, with fibres in $0^{\circ},+45^{\circ}$ and $-45^{\circ}$, are preferred in the so-called root area [13].

Although the NCF stitching process enables the production of very low crimp textiles, it can damage the fragile fibres, and cause some disturbance of the fibres as these are pushed aside by the stitching needles. In NCF layers with $0^{\circ}$ or $90^{\circ}$ oriented fibres, so-called "channels" are created (see Fig. 1b). In NCF fibre layers with an orientation between $0^{\circ}$ and $90^{\circ}$, like for example in $\pm 45^{\circ} \mathrm{NCFs}$, diamond-shaped "openings" are created (see Fig. 1b). These channels and openings are usually found to have a benefical effect on the permeability of the fabric [14-17]. This permits the use of various liquid resin infusion techniques for the production of composites. The most used production route for wind turbine blades based on NCFs is that of vacuum-assisted resin infusion. The imperfections caused by the stitching can, however, also have a significant effect on mechanical properties of the fabric and the final composite [18-31]. Varying degrees in reduction of the tensile and compressive strength, for example, have been noted as compared to those of equivalent UD tape based composites. Several researchers have indicated that the stitching sites seem to be preferred places for in-plane matrix crack formation.

General areal densities of the reinforcing NCFs used in the wind industry are around $1000 \mathrm{~g} . \mathrm{m}^{-2}$. Some very common styles are for example $1250 \mathrm{~g} . \mathrm{m}^{-2}$ for quasi-UD fabrics and 800 g.m ${ }^{-2}$ for $\pm 45^{\circ}$ fabrics, the latter having $400 \mathrm{~g} . \mathrm{m}^{-2}$ in each of the two fibre directions. Areal 
density ranges available from producers, however, span all types from $400 \mathrm{~g} . \mathrm{m}^{-2}$ to more than $2500 \mathrm{~g} . \mathrm{m}^{-2}$ [32-35].

\section{Fatigue of wind turbine blades}

Fatigue failure implies the failure of a structure due to repeated loading, while the load level remains well below the (quasi-static) strength of the material. As rotor blades undergo more than $10^{8}$ loading cycles [36] during a lifetime of 20 years, it is no wonder that preventing fatigue failure is one of the most important issues within the design process of wind turbine blades.

Fatigue loads on wind turbines are fairly difficult to characterise, because their amplitude varies greatly. The intensity of these variations depends on the wind environment of the turbine. The latter is usually characterised in terms of a 50-year extreme wind speed, a frequency distribution of the wind speed, and reference turbulence. As mentioned above, based on the wind conditions, the loads acting at different locations in the blade can be simulated. This can be done by means of various modelling techniques, and measurements of loads on prototype turbines are used as a verification of the simulated loads.

\subsection{Basic fatigue design philosophy}

The basic fatigue design philosophy for wind turbine blades is rather conservative and mostly inherited from the design of steel structures. Although the actual wind loads on turbine blades are continuously varying and random in nature, for the purpose of material fatigue testing, they are usually discretised. The accumulated load spectrum is determined by means of the "rain flow counting" algorithm [12,37-39]. This defines so-called "load bins" with a mean stress/strain, a certain stress/strain range and the corresponding number of cycles. Guidelines for the minimum number of bins, which is related to the desired resolution of the wind load distribution, can be found in the relevant standards, e.g. [4]. This discretisation procedure of the load spectrum allows for material fatigue tests to be carried out under cyclic loading with constant amplitude.

In the next step, Goodman diagrams, or constant life diagrams (CLD), of the applied material are determined, based on constant amplitude fatigue testing of coupon specimens. To obtain meaningful CLDs, $S-N$ curves for different stress ratios $R$ (minimum stress divided by maximum stress) are needed. It is recommended to test at least for $R=0.1, R=-1$ and $R=10$ [37]. If no $S-N$ data are available for the material, the Goodman diagram may also be calculated based on the characteristic static strength of the material and appropriate safety factors [4].

Subsequently, the Palmgren-Miner rule, again in combination with appropriate safety factors, is used for calculating the accumulated damage over the lifetime of the blade $[4,12,38]$. The basic idea of this approach is as follows: first the "damage" associated with each of the load bins is determined, based on the Goodman diagrams. For each relevant load level, the ratio between the actual number of cycles $\left(n_{i}\right)$ and the maximum number of cycles to failure $\left(N_{i}\right)$ is calculated. This ratio is then summed over all load conditions, to obtain the damage parameter $D$ :

$$
D=\sum_{i} \frac{n_{i}}{N_{i}}
$$

If $D$ is higher than a critical value (equal to 1 in many cases), fatigue failure of the material is predicted.

Comparison of the above-described "constant amplitude approach" with detailed variable amplitude tests has shown that it introduces a considerable amount of modelling uncertainty and that it is important to test coupons at stress ratios and ranges that are critical for the calculated fatigue life of the blade structure to limit the uncertainty [40-42]. Apart from that, it should also be kept in mind that dealing with composites is not the same as dealing with metals or other isotropic materials. Damage and failure modes are very different. Another aspect that is not taken into account in this approach is the possible influence of the sequence of loading: high loads followed by low loads may not produce the same effect as low loads followed by high loads.

\subsection{Material testing}

Normally, relevant mechanical material tests, such as fatigue tests, are carried out on coupons and on subcomponents, both having a representative lay-up and a processing route similar to that of the blade in question. The procedure described above for the fatigue life estimation is based on the assumption that the coupon fatigue strength is representative of the strength of the laminates in the full-scale composite structure. However, in full-scale blades, certain manufacturing defects and imperfections may be present that are not normally found in small scale coupons. As these can be very important for the strength, the final qualification of the blade design and material often requires a full-scale test on a prototype blade. Some types of defects however, are small and distributed throughout the material, like for example the NCF artefacts discussed above. These are taken into account in the material testing, provided that the test specimens are taken from a batch of material that is representative for the production of the blades. The types of coupon and full-scale blade testing that are required have been described in several standards and guidelines; e.g. by DNV, GL and IEC [2-4,8-10,43].

\subsection{Uncertainties in material properties}

Veldkamp [39] has stated that the uncertainties in material fatigue properties and life prediction methods dominate the total uncertainty for blade materials, and hence determine the required partial safety factors. If the extent and effect of the defects or artefacts in a material is not fully understood, it is necessary to use very large 
safety factors to account for the uncertainty. Current design schemes are oriented primarily towards trying to minimise the risk of failure due to material uncertainties, not towards a more thorough characterisation of the material and these uncertainties, or the effect of imperfections or defects on the properties. This leads to "overdesigning", with generally a higher cost and a lower reliability as a consequence. A more profound understanding of the material behaviour and the influence of defects could result in a significant reduction of the required safety margins and therefore mean considerable cost and weight savings.

\section{Fatigue of UD GFRPs}

As mentioned earlier, for most wind turbine blades, glass fibre composites are the material of choice. The fatigue properties of glass fibre composites have been under investigation for several decades. The early works are mostly concerned with laminates based on unidirectional (UD) "tape" or "prepreg" layers, which are consolidated in an autoclave to produce composite parts. In more recent years (roughly the last two decades), however, the attention has shifted towards the use of textile reinforcements. The major advantage of textile reinforcements lies in the wide range of faster and more economical composite production techniques. As mentioned before, the most frequently used textiles for wind applications, the non crimp fabrics (NCF), consist of unidirectional fibre layers that are stitched together with a thin yarn (see also Fig. 1). Their main advantage is a very limited fibre crimp that translates into a composite stiffness and strength that is very close to that of an equivalent UD prepreg based laminate. There are, however, still concerns regarding the influence of the stitching process and the resulting material artefacts (see also Fig. 1b) that still remain unclear and need to be cleared out further.

The current section reviews fatigue data for various types of glass-thermoset composites. The focus is on the tension-tension fatigue behaviour of unidirectional laminates, i.e. when the stress ratio $R$ (minimum stress over maximum stress) lies between zero and one. The first section in this paragraph concerns the general fatigue behaviour of glass fibre UD laminates, mostly based on UD tapes. The second paragraph gives an overview and analysis of the fatigue behaviour of a number of quasi-UD NCF composites that are designed specifically for wind turbine blade applications.

\subsection{Fatigue aspects of "true" UD GFRP}

Systematic research into the general fatigue behaviour of (mostly prepreg based) "perfect" or "true" UD laminates mainly predates 1995 , e.g. [44-56]. Afterwards, largely under the impulse of the aviation and automotive industry, the research focus has shifted more towards carbon fibre based composites, although many researchers still test various types of glass fibre composites, albeit often as comparison for other materials. Fatigue of composites is a complicated matter, and many factors influence the fatigue behaviour. The following provides an overview of the influence of some of the more important factors, based on available research literature. The focus is on the behaviour of glass fibre composites.

\subsubsection{Loading rate}

Most glass fibre based composites are rate dependent materials. Since fatigue tests are usually done at relatively high frequencies and thus loading rates, it is important that the effect of this rate dependency is assessed. The effect of the loading rate on the fatigue life curve of a glass fibre fabric composite is illustrated in Figure 5a, showing a distinct increase in the fatigue life for higher loading rates. Short-term ultimate strength tests at both the normal loading rate $\left(1-5 \mathrm{~mm} . \mathrm{min}^{-1}\right)$ and at a rate equivalent to the fatigue loading rate (e.g. $1 \mathrm{~m} . \mathrm{min}^{-1}$ ) can give an idea of the rate sensitivity of the material under study. To eliminate the loading rate effect from the experimental fatigue life curve, the frequency for the individual fatigue tests can be adapted with respect to the maximum applied fatigue stress level, in such a way that the resulting loading rate is approximately the same for all points on the fatigue life curve. Sims [57] for example showed that if the fatigue life curves for different loading rates are normalised with respect to the static strength at that loading rate, the curves will approximately coincide. This also implies that when the static strength is included in a fatigue life curve, this too should be the static strength obtained for a loading rate comparable to that in the fatigue tests. The importance of the rate effect on the strength of glass composites is made clear by the data in Figure 5b.

Additionally, it is also important to restrict the loading rate and thus the fatigue test frequency to avoid autogenous heating. For glass fibre composites, this can be important. Usually, the frequency is restricted so that the temperature rise in the material is limited to about $10^{\circ} \mathrm{C}$. In practice, the frequency is between 1 and $25 \mathrm{~Hz}$, depending on the type of composite being tested.

\subsubsection{Constituent materials}

The constituent materials of the composites can play an important role in the fatigue performance. Konur and Matthews [53] have published an interesting review on early research on this subject.

It has been shown that the glass fibre type can influence the fatigue behaviour to a large extent. The early work in this field was done by Boller in the 1960's [47]. He compared the fatigue behaviour of composites produced with higher modulus $S$-glass to that of composites with the lower modulus $E$-glass. He found that the former had a much better fatigue performance. The same conclusion 


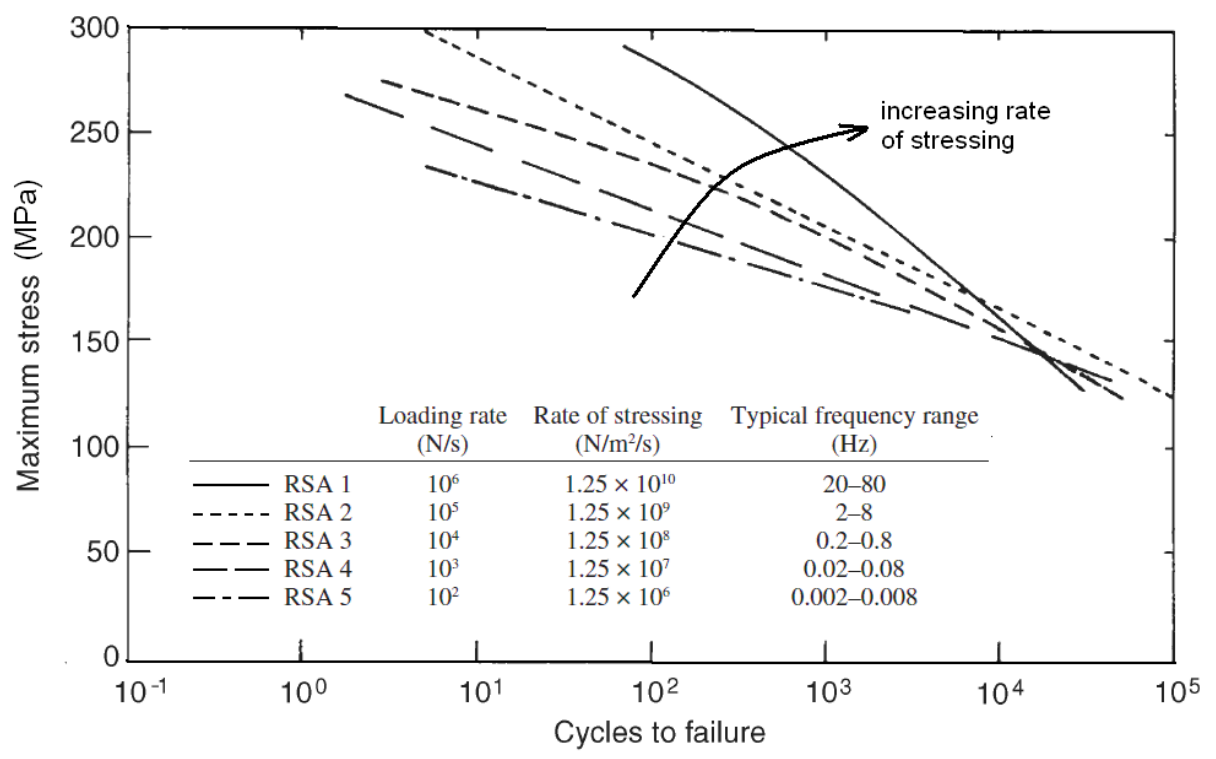

(a)

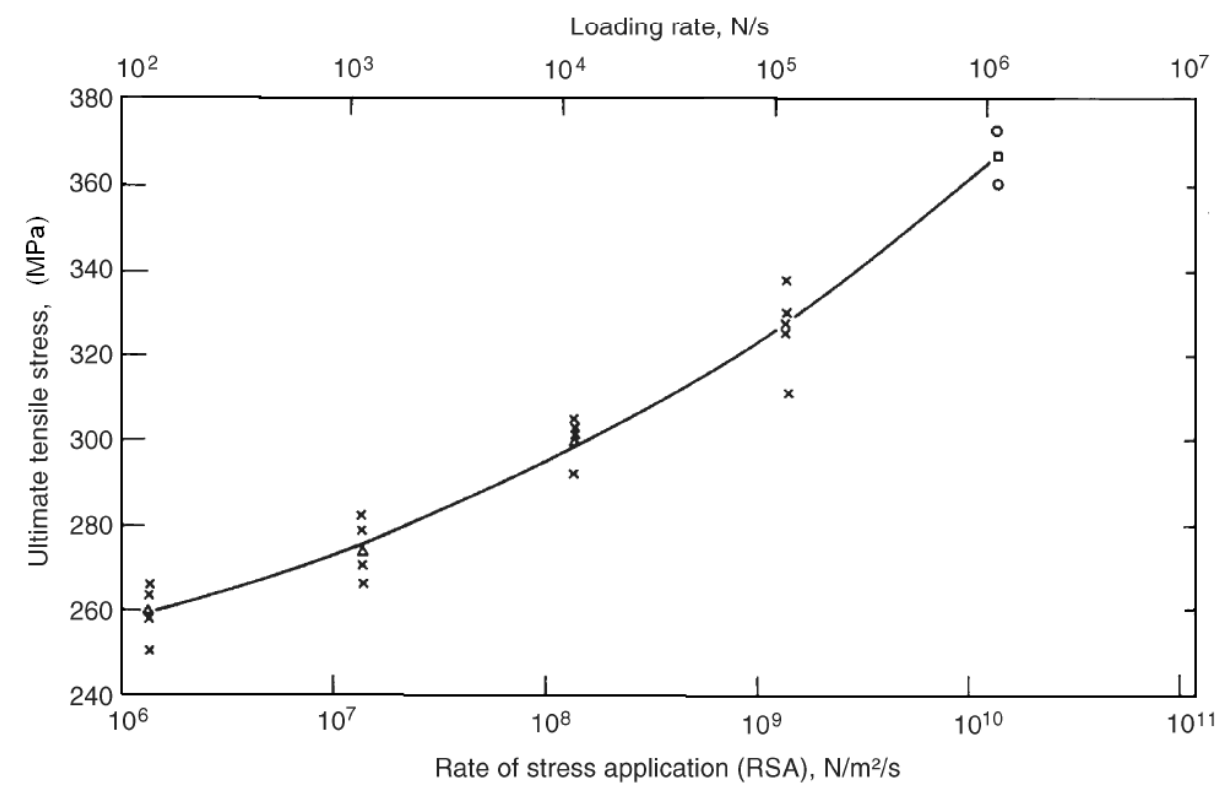

(b)

Fig. 5. (a) Illustration of the effect of the RSA (rate of stress application) on the fatigue behaviour of a glass fibre fabric/epoxy composite. (b) the effect of the loading rate on the ultimate tensile strength of the same material. Adapted from [57].

was later reached by other researchers $[51,58,59]$. In general, composites containing fibres with a relatively low stiffness tend to have steeper normalised $S-N$ curves (i.e. shorter fatigue life for the same applied stress conditions) than those containing fibres with a high modulus [53]. Talreja [60] explained this effect by stating that in the case of crack bridging by the fibres, crack opening is restricted more when using high modulus fibres.

The influence of the matrix material has also been investigated by several researchers in the past $[44,45,50$, 58,61-63]. For thermoset resins, the difference seems to be rather small, although it is observed that matrices with a higher toughness result in composites with a somewhat improved fatigue performance, e.g. in $[51,58,61,64]$.

\subsubsection{Influence of stress ratio}

If the fatigue life curves of UD glass fibre composites are normalised by dividing the maximum applied fatigue stress by the static strength of the material, it can be seen that the slope of the $S-N$ curve depends on the value of 


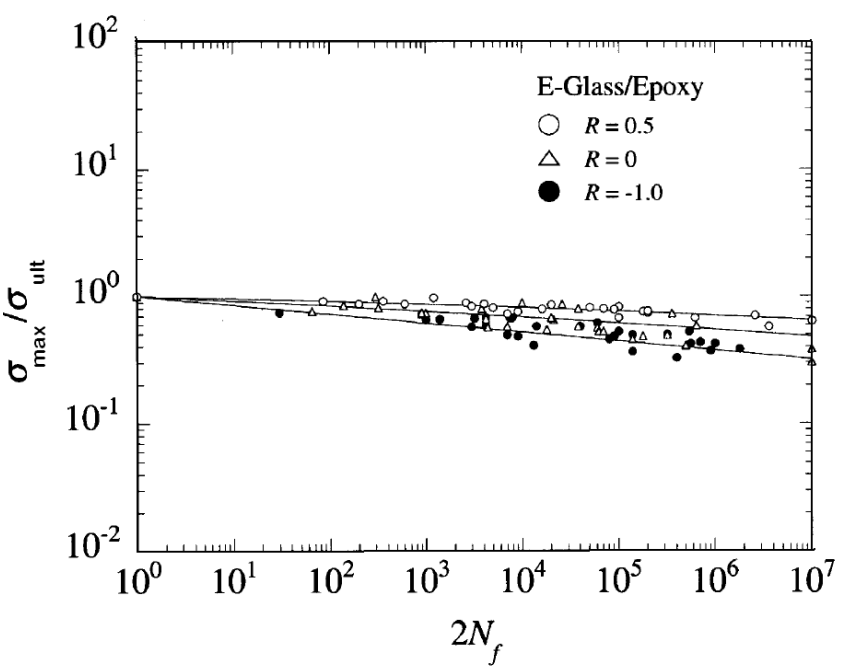

(a)

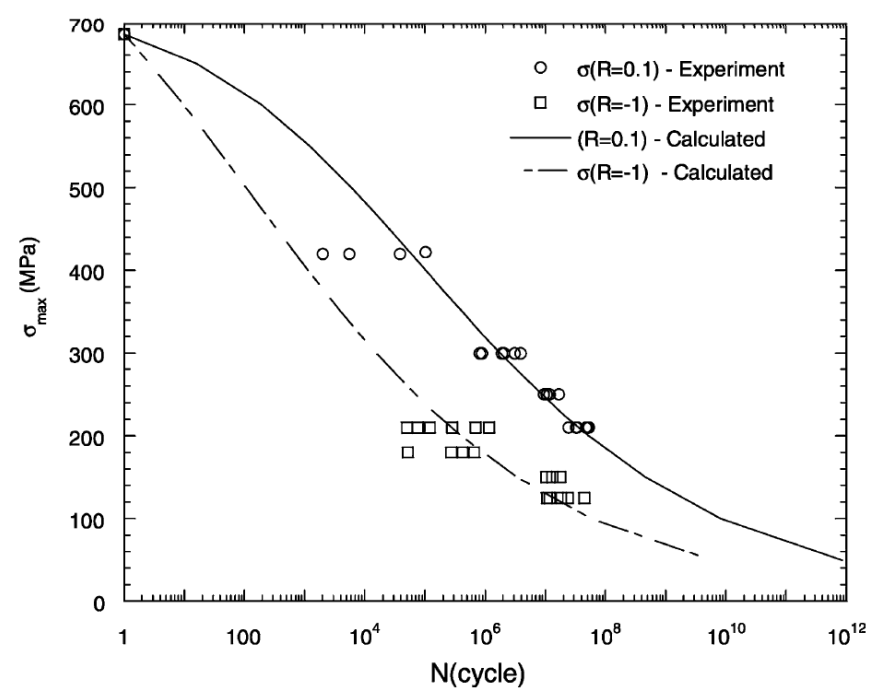

(b)

Fig. 6. Illustration of the effect of the stress ratio $(R)$ on the slope of the normalised fatigue life curve. (a) the results of El Kadi and Ellyin [56], On the $X$-axis, the number of "halfcycles" to failure is plotted. ( $\log -\log$ scale, frequency $=3.3 \mathrm{~Hz})$. (b) the results of Bach [66] ( $0^{\circ}$ glass-Polyester, $V_{\mathrm{f}}=35 \%$, loading rate $=3 \mathrm{kN} . \mathrm{s}^{-1}$.

the stress ratio. El Kadi and Ellyin [56] studied this influence for a prepreg-based unidirectional glass fibre-epoxy composite. Their results, illustrated in Figure 6a, showed that the slope of the normalised fatigue life curve for an $R$-factor of 0.5 was smaller than that for an $R$-factor of 0 , which in turn was smaller than that for an $R$-factor of -1 (complete reversal of the load). This means that for the same material, the fatigue life is higher for a pure tensile stress fatigue situation than for a tension-unloading (or tension-compression) condition (i.e. $R$ between -1 and 0 ). A similar conclusion was reached in [65-67]. The results of Bach [66] are shown in Figure 6b.

\subsubsection{Fibre volume fraction}

The influence of the fibre volume fraction $\left(V_{\mathrm{f}}\right)$ of a composite on the fatigue behaviour is somewhat two-fold. Increasing the fibre volume fraction increases the static strength, implying that also the fatigue strength on the whole will be improved (the fatigue life curve will be shifted towards higher stresses). However, if the fatigue life curves for the same type of material but with different $V_{\mathrm{f}}$ are normalised with respect to the respective static strengths $\left(\sigma_{\mathrm{ULT}}\right)$, as was done in Figure 7 for the results of Dharan [49] for a type of UD E-glass/epoxy composite, it becomes clear that the relative degradation rate for composites with higher $V_{\mathrm{f}}$ is higher than for composites with a lower $V_{\mathrm{f}}$. If the normalised fatigue life curve is approximated by a straight line on a linear-logarithmic scale, this line can be described by the following equation:

$$
\sigma_{\max } / \sigma_{\mathrm{ULT}}=1-b \log N_{\mathrm{f}}
$$

in which the parameter $b$ represents the slope of the curve. In the case of Figure 7, increasing the fibre volume fraction from 0.16 to 0.50 increases the slope parameter $b$ from about 0.085 to 0.1 (see also Fig. 10).

\subsection{Fatigue of quasi-UD fabric composites for wind turbine blades}

As discussed earlier, most manufacturers of wind turbine blades employ textiles or fabrics as reinforcement rather than using prepregs or filament winding. In most cases, non crimp fabrics are used. It was already pointed out earlier that, for material testing, it is very important that the actual processing conditions for the blades are approximated as closely as possible in the production of the test material. When using textiles, there is the added complication of the production of the textiles themselves. The production of test laminates represents an additional source of variation in the material results as the laminate's microstructure is determined by the manner of fabric making and the conditions and procedures used to impregnate it. While the influence of the conditions and procedures of laminate preparation have been considered in some publications, e.g. in $[68,69]$, the way how "identical" fabric designs are manufactured is still the source of numerous differences in test results and changes of mechanical property data.

Over the past decades a vast amount of data has been generated on the fatigue behaviour of glass fibre NCF composites. Major parts of these data are produced in the scope of wind industry related projects. Two main publicly accessible databases are available containing various fatigue data on glass fibre NCF based composites for the wind industry: the (European) OPTIDAT database, containing the results of the OPTIMAT BLADES project [70] and the (American) DOE/MSU database [71], containing results of an elaborate fatigue test program spanning about twenty years. Several reports [72-76], papers and student theses have been 


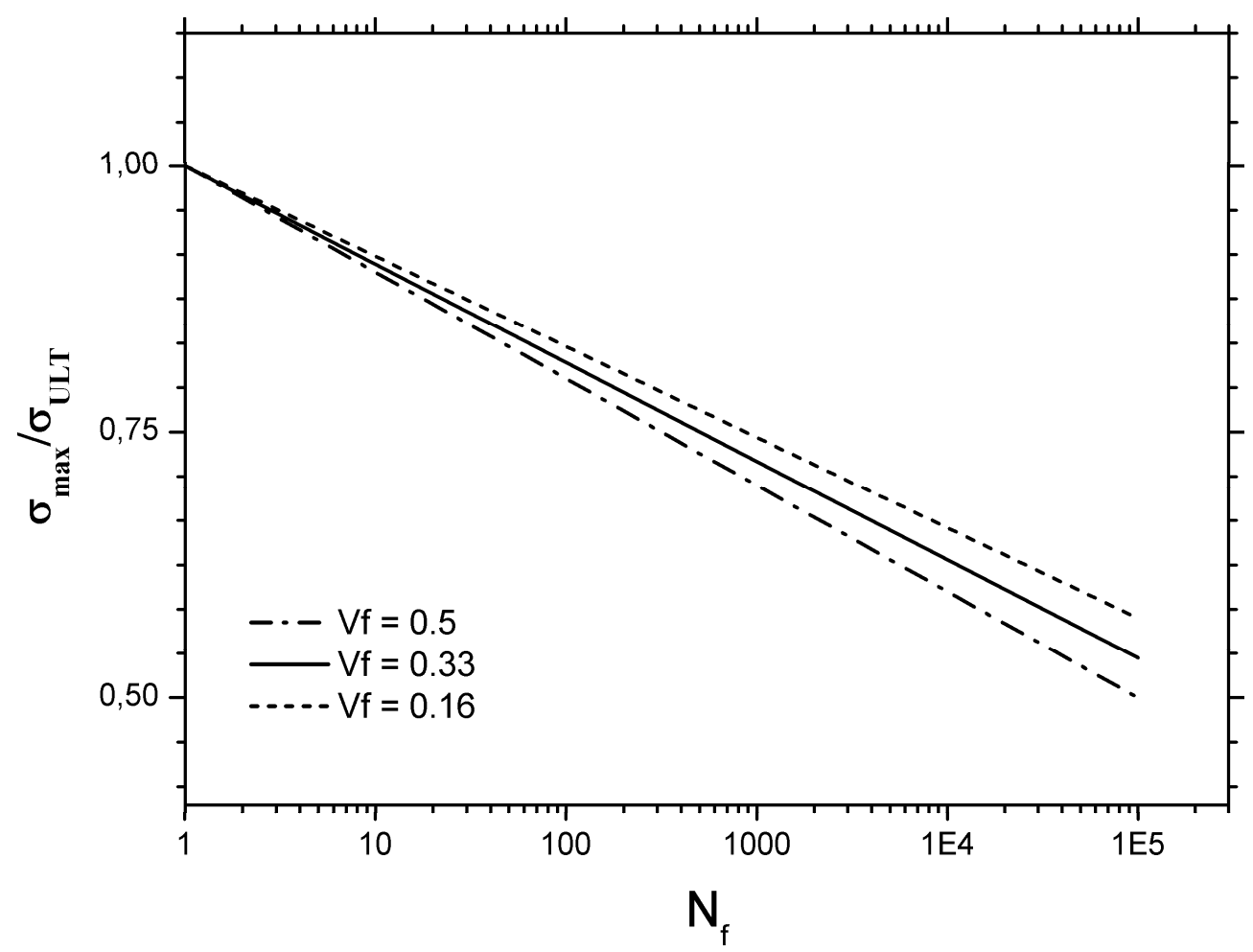

Fig. 7. The influence of the fibre volume fraction on the slope of the normalised fatigue life curve of a $0^{\circ}$ unidirectional $E$-glass/epoxy composite. Frequency: $2-4 \mathrm{~Hz}, R$-ratio: 0.1. Based on the data of Dharan [49].

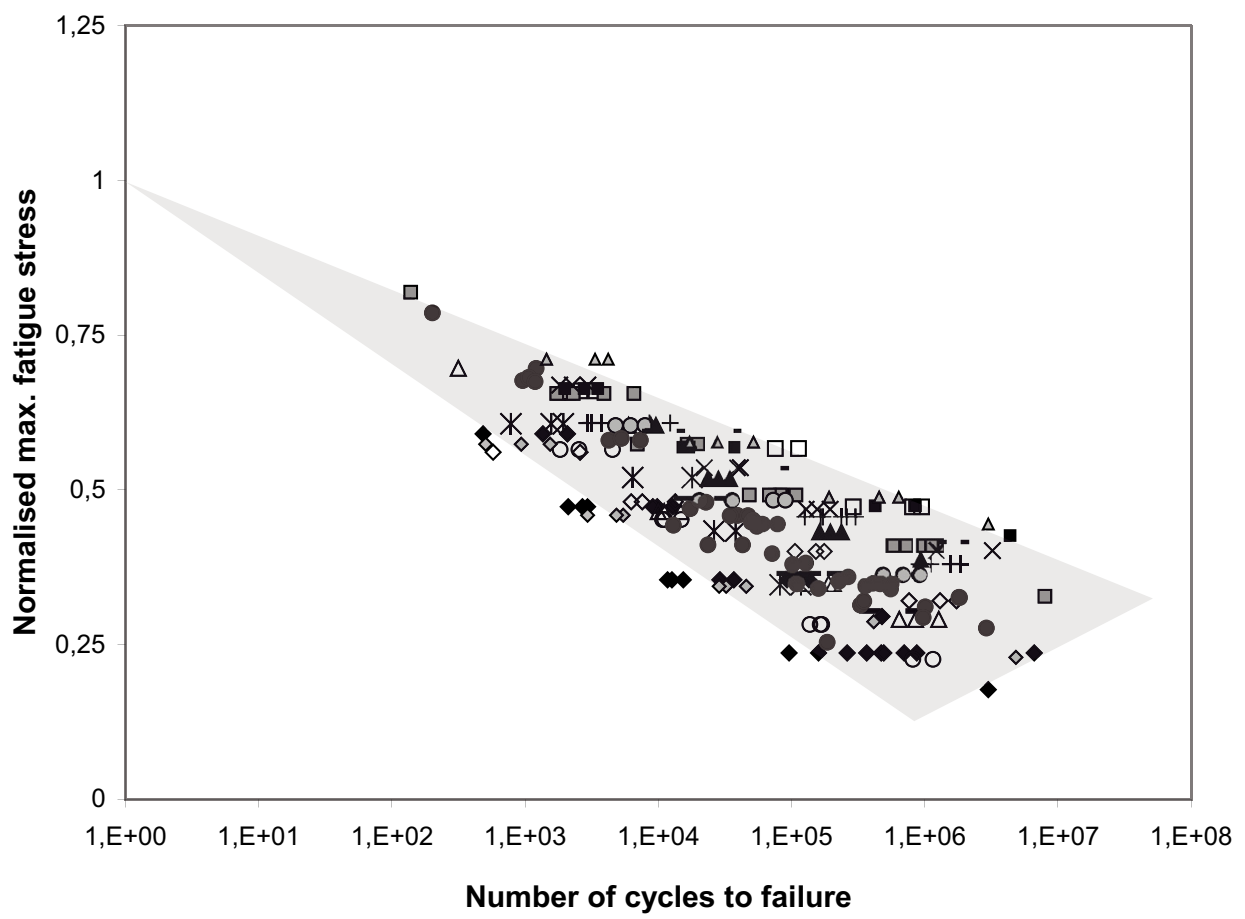

Fig. 8. The fatigue life data for various types of quasi-UD $0^{\circ}$ composites, collected from the OPTIDAT database and the DOE/MSU database. Different symbols indicate different types of composites. 
published on the data and its analysis. An extensive list of these publications can be found in [71].

Although the vast majority of the data in these two databases is for mixed orientation $\left(0^{\circ} / \pm 45^{\circ}\right)$ laminates with varying percentages of $0^{\circ}$ oriented fibres, they do also contain some fatigue results for quasi-UD NCF composites under tensile loading conditions in the fibre direction. These data were filtered out from the databases and are collected in Figure 8. The data have been normalised by dividing the maximum fatigue stress by the average tensile strength of the materials (ranging from about $700 \mathrm{MPa}$ to about $1200 \mathrm{MPa}$ ). If the data for each type of material is approximated as in Equation (2), then it is clear that there is a considerable variation in the slope parameter $b$. For fibre-dominated fatigue in composites with well-aligned fibres, $b$ is usually lower than or equal to 0.1 , as in Figure 7, where $b$ ranges from 0.085 to 0.1 . The slopes for the data in Figure 8 range from about 0.09 to about 0.15 . This indicates that both "good" and "bad" fatigue behaviour were observed for quasi-UD composites. As was done for "true" (prepreg-based) UD laminates above, different aspects influencing the fatigue behaviour of quasi-UD NCF composites were analysed based on the available data.

\subsubsection{Constituent materials}

Quasi-UD NCFs usually consist only of two layers: the main $0^{\circ}$ layer and a layer of a limited number of $90^{\circ}$ oriented yarns that provides stability. In some cases, the latter is replaced by a random fibre mat. The main differences between a $0^{\circ}$ laminate produced from prepregs and one produced from quasi-UD NCFs are thus the presence of the stitching itself and the disturbance of the fibres in the immediate surroundings of the stitching site (see Fig. 1b), as well as the presence of a limited amount of $90^{\circ}$ or randomly oriented material.

In the scope of the DOE/MSU database, interesting data were generated that allow for the analysis of the influence of the presence of the stitching yarn in the final composite, see Figure 9a. The data points indicated with open markers show the (normalised) fatigue life results for two types of unidirectional composites based on quasi-UD NCFs. The filled markers show the fatigue results for the same materials, where the researchers had removed the NCF stitching yarn prior to impregnation of the fabrics. Unfortunately, it was not mentioned explicitly in what way the removal of the yarn was done, so it is unclear how the structure of the fabric was influenced by this process. Nonetheless, as the figure shows, removing the stitching seems to result in a considerable improvement in the fatigue life. For the first type of quasi-UD NCF composite (denoted as material A), the slope parameter $b$ (see Eq. (2)) decreases from 0.12 to 0.1 if the stitching is removed. For the second type of composite (denoted as material B), it decreases from 0.13 to 0.11 . This means an increase in the maximum fatigue stress for a fatigue life of $10^{6}$ cycles of about $45 \%$ for the first material and about
$55 \%$ for the second. Even though systematically removing the stitching from quasi-UD NCFs before impregnation would be highly impractical and even impossible to implement on a large scale, these results are important, because they indicate that the influence of the stitching is not negligible. It can therefore be expected that differences in the stitching parameters (length of a stitch, gauge length, stitching yarn tension, stitching pattern, etc.) may also affect the fatigue behaviour of the resulting composite. Although the databases contain results on several different (commercial) types of quasi-UD NCFs, the exact stitching parameters are not specified, and the resulting fabric parameters are not characterised. An indepth materials study, analysing the effect of the fabric production parameters on the final behaviour of the composite would be very valuable in clarifying this matter. Although for carbon fibre NCFs, some work on this subject has been done $[18,77]$, research on the topic for glass fibre NCFs seems to be very scarce, despite their importance in fatigue-sensitive applications like wind turbines.

Most of the results in the databases for quasi-UD NCF composites are for composites with a polyester resin matrix. For triaxial NCF composites, however, the researchers did analyse the influence of different matrix materials (vinylester, polyester and epoxy) on the fatigue life curve. They found little or no effect of the matrix material on the fatigue life $[72,78]$.

\subsubsection{Influence of stress ratio}

For tensile-tensile fatigue of quasi-UD NCF based $0^{\circ}$ composites, the databases only contain data for stress ratios $R$ equal to 0.1 . Conclusions with regard to the tensile slope parameter for other $R$ values can therefore not be made. However, there exists evidence that the behaviour is again similar to that of "true" UD laminates: for pure compressive fatigue (e.g. $R=10$ ), the slope of the normalised fatigue life curve is found to be slightly lower than for tensile fatigue (0.6-0.9 compared to 0.9-0.15) [78]. This means that in pure compression, the materials are relatively less fatigue sensitive than in pure tension. Fully reversed bending $(R=-1)$ fatigue test results for the quasi-UD NCF materials are not included in the database, but from the data for multidirectional laminates with at least $25 \%$ fibres in the $0^{\circ}$ direction, it can be concluded that the fatigue behaviour in this case is worst, as it is for "true" pure UD laminates [73].

\subsubsection{Influence of fibre volume fraction}

Mandel et al. [73] described the average fatigue life curve for the database materials by means of Equation (1), and concluded that, as for "true" UD composites (see above), there is a significant influence of the fibre volume fraction on the fatigue life of the tested quasi-UD NCF composites. They noted a transition from "good" fatigue behaviour to "poor" fatigue behaviour (i.e. an increasing slope parameter $b$ ) for an increasing fibre volume 


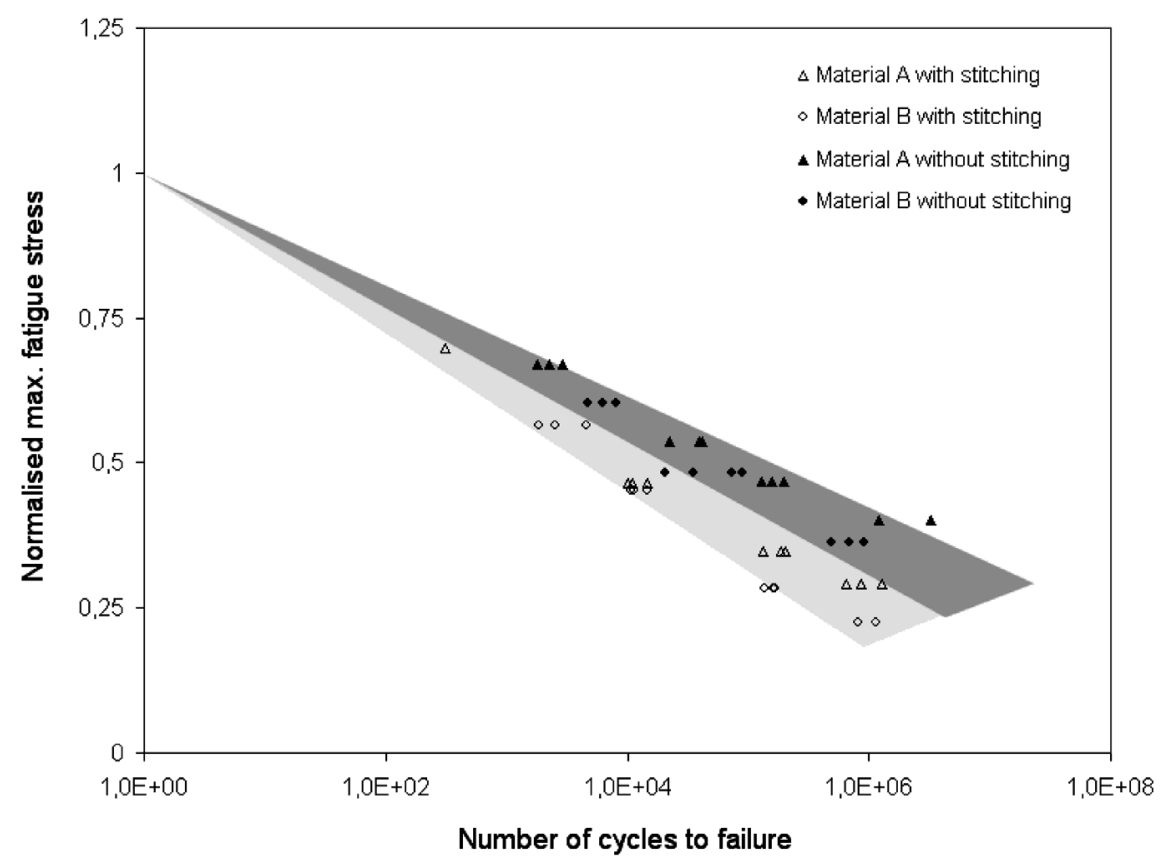

(a)

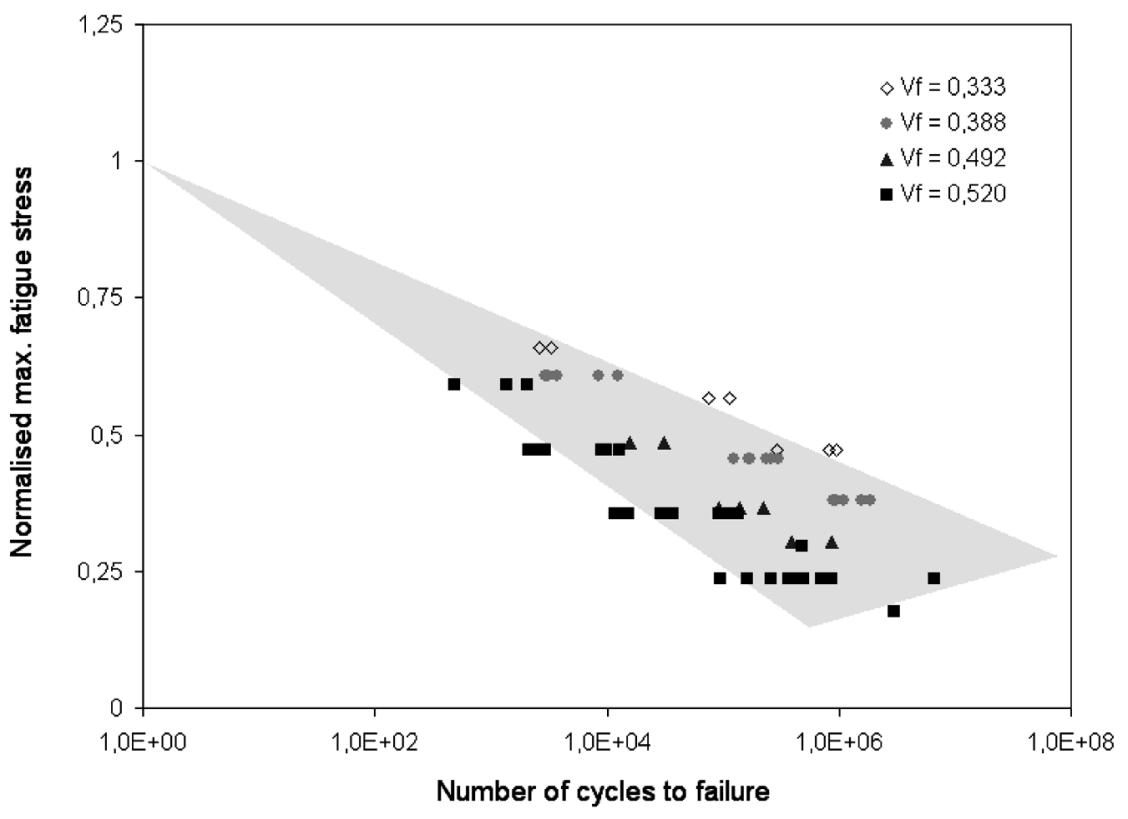

(b)

Fig. 9. (a) Fatigue life results for two types of quasi-UD based $0^{\circ}$ laminates. Open markers indicate the laminates with the stitching in place, filled markers represent the results for laminates in which the stitching yarn had been removed prior to impregnation. (b) Fatigue life data for four different fibre volume fractions of the same type of material. Data from DOE/MSU database.

fraction. This is illustrated in Figures $9 \mathrm{~b}$ and 10. Figure 9b shows the normalised fatigue life curves for four different fibre volume fractions of the same type of quasi-UD NCF material tested in the $0^{\circ}$ direction, while Figure 10 plots the slope parameter $b$ as a function of the material fibre volume fraction for several of the materials in the database. For comparison, the values for the slope parameter calculated based on the fatigue data of Dharan [49] for a "pure" UD glass fibre composite material are also shown in the figure, indicating a similar trend, albeit less pronounced.

\section{Conclusions and outlook}

This paper has presented an overview of different design and material aspects related to wind turbine blades. 


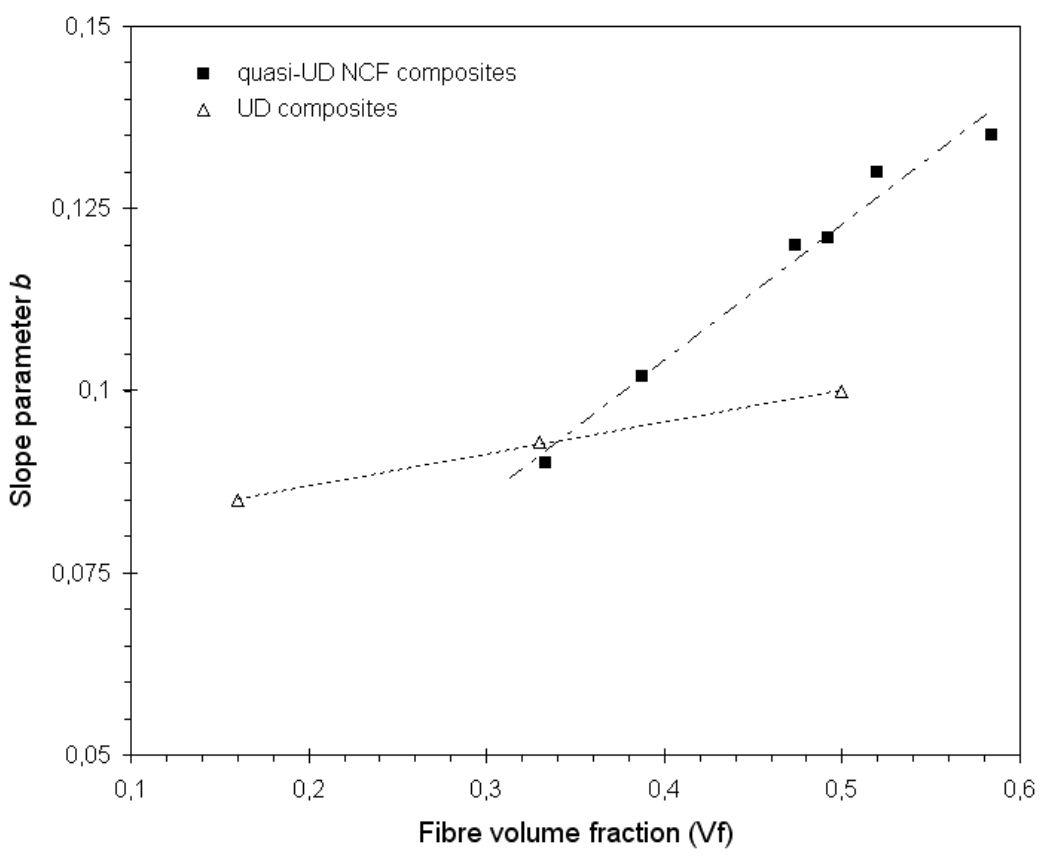

Fig. 10. The slope parameter $\mathrm{b}$ as a function of the fibre volume fraction for $0^{\circ}$ quasi-UD NCF composites (filled markers, data calculated based on DOE/MSU database results). For comparison, the data for a type of "pure" UD glass fibre composite are also shown (open markers, data calculated based on the results of Dharan [49], see also Fig. 7).

A main concern in the design of these structures is the fatigue behaviour of the material, which is usually a type of glass fibre composite. Uncertainty in the material fatigue properties (as well as in the life prediction methods) often dominates the total uncertainty for turbine blades and causes "overdesigning" by giving rise to large safety factors. To safely reduce this amount of overdesign, the material behaviour in all its aspects must be known thoroughly. For wind turbine blades, where NCFs are routinely used as a reinforcement, this means that the influence of the fabric stitching process and the artefacts it produces on the final performance of the composite needs to be characterised. Over the years, large databases have been built containing data on the fatigue behaviour of several (commercially available) types of NCF composites. As for "pure" UD composites, several interesting influencing parameters can be identified from these data. However, a more fundamental insight in the influence of the NCF fabric structure on the properties of the resulting composite remains vital. Such an understanding, in combination with a full characterisation of the mechanical behaviour, will lead to the production of more optimised fabrics and, by limiting the "overdesign", to important material savings.

\section{References}

[1] M. Zvanik, OC presentation at CFA show, Tampa, Florida, 2001

[2] IEC 61400-1, Wind turbines, Part 1: Design requirements, edition 3, International Electrotechnical Commission, 2005
[3] Guideline for the certification of offshore wind turbines, Germanische Lloyd, 2005

[4] Guideline for the certification of wind turbines, with supplement 2004, Germanische Lloyd, 2003

[5] http://www.gl-group.com

[6] http://www.DNV.com

[7] http://www.tuv.com

[8] Guidelines for Design of Wind Turbines, Det Norske Veritas and Risø National Laboratory, 2002

[9] Offshore standard DNV-OS-J101 Design of offshore wind turbine structures, Det Norske Veritas, 2004

[10] Offshore standard DNV-OS-J102 Design and manufacture of wind turbine blades, Offshore and onshore wind turbines, Det Norske Veritas, 2006

[11] C.W. Kensche, Fatigue of composites for wind turbines, Int. J. Fatigue 28 (2006) 1363-1374

[12] Gurit, Section 2: Structural Design, in Wind energy composite materials handbook, downloadable from: http:// www.gurit.com

[13] T. Burton, D. Sharpe, N. Jenkins, E. Bossanyi, Wind Energy Handbook, 2001, John Wiley \& Sons

[14] S. Drapier, A. Pagot, A. Vautrin, P. Henrat, Influence of the stitching density on the transverse permeability of non-crimped new concept (NC2) multiaxial reinforcements: measurements and predictions, Compos. Sci. Technol. (2002) 1979-1991

[15] T.S. Lundström, The permeability of non-crimp stitched fabrics, Compos. Part A 31 (2000) 1345-1353

[16] M. Nordlund, T.S. Lundström, Numerical Study of the Local Permeability of Noncrimp Fabrics, J. Compos. Mater. 39 (2005) 929-947

[17] M. Nordlund, T.S. Lundstrom, V. Frishfelds, A. Jakovics, Permeability network model for non-crimp fabrics, Composites Part A: Appl. Sci. Manufacturing, Selected 
Contributions from the 7th International Conference on Flow Processes in Composite Materials held at University of Delaware, USA 37 (2006) 826-835

[18] L.E. Asp, F. Edgren, A. Sjögren, Effects of stitch pattern on the mechanical properties of non-crimp fabric composites, in ECCM 11, Rhodos, 2004

[19] F. Edgren, D. Mattsson, L.E. Asp, J. Varna, Formation of damage and its effects on non-crimp fabric reinforced composites loaded in tension, Compos. Sci. Technol. 64 (2004) 675-692

[20] S.V. Lomov, D.S. Ivanov, K. Vallons, I. Verpoest, D.V. Klimshin, T.C. Truong, Peculiarities of damage behaviour of NCF carbon/epoxy laminates under tension, in ICCM 16, Kyoto, Japan, 2007

[21] K. Vallons, The behaviour of carbon fibre-epoxy NCF composites under various mechanical loading conditions, Doctoral dissertation, Dept. of Metallurgy and Materials Engineering, Katholieke Universiteit Leuven, 2009

[22] K. Vallons, S.V. Lomov, I. Verpoest, Fatigue and postfatigue behaviour of carbon/epoxy non crimp fabric composites. in 16th international conference on composite materials, Kyoto, Japan, 2007

[23] K. Vallons, S.V. Lomov, I. Verpoest, Damage evolution in static and fatigue tensile loading of carbon/epoxy NCF composites, in ECOMAS Thematic Conference on Mechanical Response of composites, Porto, 2007

[24] K. Vallons, S.V. Lomov, I. Verpoest, Mechanical properties and damage evolution during static and fatigue loading of carbon-epoxy ncf composites, in Sampe Europe International Conference '07, Paris, 2007

[25] T.C. Truong, M. Vettori, S. Lomov, I. Verpoest, Carbon composites based on multi-axial multi-ply stitched preforms, Part 4. Mechanical properties of composites and damage observation, Composites Part A 36 (2005) 12071221

[26] M. Vettori, T.T. Chi, S.V. Lomov, I. Verpoest, Progressive damage characterization of stitched, biaxial, multi-ply carbon fabrics composites, in ECCM 11, Rhodos, 2004

[27] V. Carvelli, T.T. Chi, M.S. Larosa, S.V. Lomov, C. Poggi, D.R. Angulo, I. Verpoest, Experimental and numerical determination of the mechanical properties of multi-axial multi-ply composites, in ECCM 11, Rhodos, 2004

[28] G.A. Bibo, P.J. Hogg, M. Kemp, Mechanical characterisation of glass- and carbon-fibre-reinforced composites made with non-crimp fabrics, Compos. Sci. Technol. 57 (1997) 1221-1241

[29] A.P. Godbehere, A.R. Mills, P. Irving, Non-crimp fabrics versus prepreg CFRP composites - A comparison of mechanical performance, in 6th international conference on fibre reinforced composites - FRC'94, Newcastle, 1994

[30] P.A. Smith, Carbon Fiber Reinforced Plastics-Properties (2.04), in Comprehensive Composite Materials, Elsevier Sciences Ltd, 2000, pp. 107-150

[31] S. Sandford, L. Boniface, S.L. Ogin, S. Anand, D. Bray, C.R. Messenger, Damage accumulation in noncrimp fabric based composites under tensile loading, in Proceedings of the Eighth European Conference on Composite Materials, ECCM-8, 1998, Naples, Italy, Woodhead Publishing, Cambridge, UK

[32] Company product information Owens Corning: Double Bias Fabrics $\left( \pm 45^{\circ}\right)$
[33] Company product information Owens Corning: Quadriaxial Fabrics $\left(0^{\circ} / 90^{\circ} / \pm 45^{\circ}\right)$

[34] Company product information Owens Corning: Triaxial Fabrics $\left(0^{\circ} / \pm 45^{\circ}\right.$ OR $\left.90^{\circ} / \pm 45^{\circ}\right)$

[35] Company product information Owens Corning: Unidirectional Fabrics $\left(0^{\circ}\right.$ or $\left.90^{\circ}\right)$

[36] C.W. Kensche, Fatigue of materials and components for wind turbine rotor blades, Office for official publications of the European communities, 1996

[37] J. Wedel-Heinen, J. KrygerTadich, Qualification of materials and blades for wind turbines, in Ris $\varnothing$ Blade Materials Symposium, 2006

[38] S. Wessels, M. Strobel, A.V. Wingerde, I. Koprek, H.G. Busmann, Improved fatigue design methods for offshore wind turbine rotor blades condisering non-linear Goodman analysis combined with finite element analysis, in EWEC, Warsaw, 2010

[39] D. Veldkamp, A probabilistic approach to wind turbine fatigue design, in EWEC, Milan, Italy, 2007

[40] B. Hayman, J. Wedel-Heinen, P. Brøndsted, Material challenges in present and future wind energy, MRS Bulletin 33 (2008), www.mrs.org/bulletin

[41] L.G.J. Janssen, A.M.V. Wingerde, C.W. Kensche, T.P. Philippidis, P. Brøndsted, A.G. Dutton, R.P.L. Nijssen, O. Krause, Reliable Optimal Use of Materials for Wind Turbine Rotor Blades, OPTIMAT BLADES, Report ECN-C-06-023, Office for Official Publications of the European Communities, Luxembourg, 2006

[42] J. Wedel-Heinen, J.K. Tadich, C. Brokopf, L.G.J. Janssen, A.M.V. Wingerde, D.R.V.V. Delft, C.W. Kensche, T.P. Philippidis, A.P. Brøndsted, G. Dutton, R.P.L. Nijssen, I. Verpoest, Implementation of OPTIMAT in Technical Standards, OPTIMAT BLADES, OB_TG6_R002 rev. 8, ENK6-CT-2001-00552 PROJECT No.: NNE5-2001-00174, 2006

[43] IEC 61400-23, Technical Specification, Wind turbine generation systems - Part 23: Full-scale structural testing of rotor blades, International Electrotechnical Commission, 2001

[44] K.H. Boller, Fatigue characteristics of RP laminates subjected to axial loading, Modern Plastics 41 (1964) 145

[45] J.W. Davis, J.A. McCarthy, J.N. Schurb, Fatigue resistance of reinforced plastics, Mater. Des. Engng. (1964) $87-91$

[46] J.W. Dally, L.J. Broutman, Frequency effects on the fatigue of glass reinforced plastics, J. Compos. Mater. 1 (1967) 424-442

[47] K.H. Boller, Fatigue fundamentals for composite materials, ASTM STP 460 (1969) 217-235

[48] D. Dew-Hughes, J.L. Way, Fatigue of fibre - reinforced plastics: a review, Compos. 4 (1973) 167-173

[49] C.K.H. Dharan, Fatigue failure in graphite fibre and glass fibre-polymer composites, J. Mater. Sci. 10 (1975) 16651670

[50] J.V. Gauchel, I. Steg, J.E. Cowling, Reducing effect of water on fatigue properties of $S$-glass epoxy composites, ASTM STP 569 (1975) 45-52

[51] J.N. Davis, G.J. Sundsrud, Fatigue data on a variety of nonwoven glass composites for helicopter rotor blades, ASTM STP 674 (1979) 137-148

[52] S.K. Joneja, Matrix contribution to fatigue behavior of glass reinforced polyester composites, J. Reinforced Plastics Compos. 6 (1987) 343-356 
[53] O. Konur, F.L. Matthews, Effect of the properties of the constituents on the fatigue performance of composites: a review, Compos. 20 (1989) 317-328

[54] P.T. Curtis, Tensile fatigue mechanisms in unidirectional polymer matrix composite materials, Int. J. Fatigue 13 (1991) 377-382

[55] M.R. Bhat, C.R.L. Murthy, Fatigue damage stages in unidirectional glass-fibre-epoxy composites: identification through acoustic emission technique, Int. J. Fatigue 15 (1993) 401-405

[56] H. El Kadi, F. Ellyin, Effect of stress ratio on the fatigue of unidirectional glass fibre/epoxy composite laminae, Compos. 25 (1994) 917-924

[57] G.D. Sims, Fatigue test methods, problems and standards, in Fatigue in composites, in: B. Harris (ed.), Woodhead publishing limited, 2003, pp. 36-63

[58] V. Giavotto, V. Wagner, M. Caslini, C. Zanotti, Consideration of early fatigue damage on damage accumulation and on delamination mechanism in composite materials structures, in 14th ICAF conference, 1987

[59] M.J. Salkind, Fatigue of composite materials, ASTM STP 497 (1982) 143-169

[60] R. Talreja, K. Anthony, Z. Carl, Fatigue of polymer matrix composites, in Comprehensive Composite Materials, Pergamon, Oxford, 2000, pp. 529-552

[61] J. Gassan, T. Dietz, Fatigue behavior of cross-ply glassfiber composites based on epoxy resins of different toughnesses, Compos. Sci. Technol. 61 (2001) 157-163

[62] M.J. Owen, G. Rose, Polyester flexibility versus fatigue behaviour of fibre reinforced plastics, Mod. Plast. 47 (1970) 130-138

[63] M.J. Owen, Fatigue, glass reinforced plastics, in: B. Parkyn (ed.), Iliffe Books, London, 1970, pp. 251-267

[64] G.M. Newaz, Influence of matrix material on flexural fatigue behaviour of unidirectional composites, Compos. Sci. Technol. 24 (1985) 199-214

[65] J.A. Epaarachchi, P.D. Clausen, An empirical model for fatigue behavior prediction of glass fibre-reinforced plastic composites for various stress ratios and test frequencies, Composites Part A Appl. Sci. Manufacturing 34 (2003) 313-326

[66] P.W. Bach, ECN investigation of polyester composite materials, in Fatigue of materials and components for wind turbine rotor blades, in: C.W. Kensche (ed.), German Aerospace Establishment, 1996, pp. 10-38

[67] P.K. Mallick, Fiber-reinforced composites: Materials, Manufacturing and Design, 3rd edition, CRC Press Taylor \& Francis Group, 2008

[68] D.S. Cairns, J.D. Skramstad, Evaluation of hand layup and resin transfer molding in composite wind turbine blade manufacturing, 2000, Sandia National Laboratories, SAND2000-1425
[69] E.B. Larsen, Pressure bag molding: manufacturing, mechanical testing, non-destructive evaluation, and analysis, 2007, Sandia National Laboratories, SAND2006-7855P

[70] OPTIMAT BLADES PROJECT, data and publications available from: http://www.wmc.eu/optimatblades.php

[71] DOE/MSU composite material fatigue database, March 31, 2010 version 19.0. Available from: http:// windpower. sandia.gov/other/973002upd0310.pdf

[72] J.F. Mandell, R.M. Reed, D.D. Samborsky, Fatigue of fiberglass wind turbine blade materials, Department of chemical engineering, Montana state university, SAND92-7005, 1992

[73] J.F. Mandell, D.D. Samborsky, DOE/MSU Composite material fatigue database: Test methods, materials, and analysis, Sandia National Laboratories, Albuquerque, NM, Contractor Report SAND97-3002, 1997

[74] J.F. Mandell, D.D. Samborsky, D.S. Cairns, Fatigue of composite materials and substructures for wind turbine blades, Sandia National Laboratories, Albuquerque, NM Contractor Report SAND2002-0771, 2002

[75] J.F. Mandell, D.D. Samborsky, D.W. Combs, M.E. Scott, D.S. Cairns, Fatigue of composite material beam elements representative of wind turbine blade substructure, National Renewable Energy Laboratory, NREL Contractor Report SR-500-24379, 1998

[76] N.K. Wahl, J.F. Mandell, D.D. Samborsky, Spectrum fatigue lifetime and residual strength for fiberglass laminates, Sandia National Laboratories, A lbuquerque, NM Contractor Report SAND2002-0546, 2002

[77] M. Wouters, Effects of fibre bundle size and stitch pattern on the static properties of unidirectional carbon-fibre non-crimp fabric composites, in Department of applied physics and mechanical engineering, division of polymer engineering, Lulea university of technology, Lulea, 2005, p. 85

[78] D.D. Samborsky, Fatigue of E-glass fiber reinforced composite materials and substructures, Montana State University, Bozeman, Montana, 1999

[79] J. Locke, U. Valencia, Design studies for twist-coupled wind turbine blades, Sandia National laboratories, SAND2004-0522, 2004

[80] Gurit, Section 3: Blade Manufacturing Process, in Wind energy composite materials handbook, downloadable from: http://www.gurit.com

[81] F. Keßling, Modellierung des aerolastischen gesamtsytems einer windturbine mit hilfe symbolischer programmierung, DFVLR, DFVLR-FB 84-10, 1984

[82] P.J. Hogg, Manufacturing challenges for wind turbines. in Advanced Manufacturing for Composite Technologies Conference, Manchester, UK, 2008 